\title{
Stereotactic body radiotherapy feasibility for patients with peripheral stage I lung cancer and poor pulmonary function
}

\author{
AIKO KOBA ${ }^{1}$, KAZUHIKO HAYASHI $^{1,2}$, OSAMU SUZUKI $^{1}$, \\ YOSHIFUMI KAWAGUCHI $^{3}$, KAZUHIKO OGAWA ${ }^{1}$ and MASASHI CHATANI ${ }^{2}$ \\ ${ }^{1}$ Department of Radiation Oncology, Osaka University Graduate School of Medicine, \\ Suita, Osaka 565-0871; ${ }^{2}$ Osaka Heavy Ion Therapy Center, Osaka, Osaka 540-0008; \\ ${ }^{3}$ Department of Radiation Oncology, Osaka Rosai Hospital, Sakai, Osaka 591-8025, Japan
}

Received August 14, 2019; Accepted November 21, 2019

DOI: $10.3892 / 01.2020 .11333$

\begin{abstract}
The aim of the present study was to evaluate the toxicity and investigate the prognostic factors of stereotactic body radiotherapy (SBRT) for peripheral stage I lung cancer in patients with poor pulmonary function. Data from 95 patients with stage I lung cancer with poor pulmonary function treated using SBRT at Osaka Rosai Hospital were retrospectively analyzed. Poor pulmonary function was defined as the forced expiratory volume \%/sec (FEV1/FVC) $<70 \%$ or percentage of vital capacity (\%VC) $<80 \%$ during pretreatment spirometry testing. The median FEV1/FVC and $\% \mathrm{VC}$ of the patients were 59.1 and $78.8 \%$, respectively. The most commonly prescribed dose of SBRT was $50 \mathrm{~Gy}$ in four fractions (68 patients, $72 \%$ ). The median follow-up period was 34 months. Four patients developed adverse effects of grade $\geq 3$, one patient developed grade 5 radiation pneumonitis, one grade 5 hemoptysis, one grade 3 radiation pneumonitis and one grade 3 chest wall pain. The 3 -year local control and overall survival (OS) rates were 78.8 and $59.9 \%$, respectively. Univariate analysis revealed that Karnofsky performance status (KPS) significantly predicted OS $(\mathrm{P}=0.037)$. Thus,
\end{abstract}

Correspondence to: Dr Kazuhiko Hayashi, Department of Radiation Oncology, Osaka University Graduate School of Medicine, 2-2 Yamadaoka, Suita, Osaka 565-0871, Japan

E-mail:k.hayashi@osaka-himak.or.jp

Abbreviations: KPS, Karnofsky performance status; GTV, gross tumor volume; CTV, clinical target volume; ITV, internal target volume; PTV, planning target volume; Fr, fraction; FEV1.0, forced expiratory volume/sec; VC, vital capacity; FEV1/FVC, forced expiratory volume \%/sec; LC, local control; OS, overall survival; CSS, cancer-specific survival; COPD, chronic obstructive pulmonary disease; SBRT, stereotactic body radiotherapy; \%VC, a percentage of vital capacity; NSCLC, non-small cell lung carcinoma; HOT, home oxygen therapy

Key words: stereotactic body radiotherapy, lung cancer, poor pulmonary function, radiation pneumonitis, home oxygen therapy
SBRT in patients with stage I lung cancer with poor pulmonary function may be effective with acceptable toxicity. A KPS score $\geq 80$ indicated good prognosis.

\section{Introduction}

Stereotactic body radiotherapy (SBRT), which was introduced by Blomgren et al in 1991 (1), aims to concentrate the radiation dose to the tumor while minimizing that to the surrounding normal tissues by accurately focusing multiple radiation beams to small target volumes. SBRT in early-stage lung cancer yields excellent local control (LC) with low toxicity (2-8).

While the standard treatment for peripheral stage I non-small cell lung carcinoma (NSCLC) is surgery, SBRT is sometimes recommended to patients who have poor pulmonary function with chronic obstructive pulmonary disease (COPD), asthma or interstitial pneumonia, or those who have previously undergone lung cancer surgery. Studies on SBRT treatment in patients with lung cancer and normal or poor pulmonary function reported that the technique may cause severe radiation pneumonitis or pulmonary toxicity, despite being generally safe $(5,8,9)$. Patients with radiation pneumonitis and poor pulmonary function may develop lethal toxicity (10). Several studies have focused on patients with poor pulmonary function. Of 176 patients with severe COPD, Palma et al (11) reported that six $(3 \%)$ exhibited grade 3 toxicity, concluding that SBRT for lung cancer patients with severe COPD was well-tolerated with acceptable toxicity. In a systematic review focusing on treatment-associated toxicity in patients with early-stage NSCLC and coexisting interstitial pneumonia, Chen et al (12) demonstrated a consistently high level of SBRT-associated mortality (16.7\%) and interstitial pneumonia-specific toxicity (18.8\%). Thus, curative treatment including SBRT should be considered in the context of high toxicity. However, the safety of SBRT in patients with lung cancer and coexisting poor pulmonary function remains unclear. The present study aimed to retrospectively evaluate the safety and effectiveness of linear accelerator-based SBRT, and the prognostic factors of overall survival (OS) were investigated in patients with peripheral stage I lung cancer and poor pulmonary function. 


\section{Materials and methods}

Patients. This study was approved by the Institutional Review Board of Osaka Rosai hospital (Sakai, Japan, approval no. 18D093g) and was conducted in accordance with the Declaration of Helsinki. This study was a retrospective evaluation of all patients with stage I lung cancer treated with SBRT at Osaka Rosai Hospital between May 2003 and December 2009. Of these patients, 95 patients presented with poor pulmonary function, based on pretreatment spirometry testing; these patients were included in the study and their data were retrospectively analyzed. The median age was 76 years (range, 60-90 years). The present study included 67 male (71\%) and 28 female (29\%) patients. In 80 patients, the disease was confirmed by histology or cytology, whereas clinical diagnosis of the apparent tumor growth was performed using serial CT in the remaining 15 patients. All tumors were classified according to the International Union Against Cancer tumor-node-metastasis classification (7th edition) (13). Patients' performance status was assessed by Karnofsky performance status (KPS) (14). The KPS describes a patient's functional status in 11 categories ranging from 100 (no symptoms) to 0 (death). A KPS score of 80-100 is defined as 'able to carry on normal activity and to work. No special care is needed'.

Poor pulmonary function was defined as a forced expiratory volume $\% / \mathrm{sec}(\mathrm{FEV} 1 / \mathrm{FVC})<70 \%$ or percentage of vital capacity (\%VC) $<80 \%$ in the pretreatment spirometry test. If the FEV1/FVC was $<70 \%$, the patient was classified as having obstructive dysfunction. If the $\% \mathrm{VC}$ was $<80 \%$, the patient was classified as having restrictive dysfunction. If the FEV1/FVC was $<70 \%$ and $\% \mathrm{VC}$ was $<80 \%$, the patient was classified as having mixed obstructive and restrictive dysfunction. Central tumor location was defined as that within $2 \mathrm{~cm}$ of the proximal bronchial tree, heart, great vessels, trachea or other mediastinal structures.

Treatment planning and delivery. All patients were immobilized in an individually shaped vacuum bag that covered them from the head to the pelvis. Each patient who, if necessary, was equipped with abdominal compression, underwent CT simulation with 5-mm thickness and a 5-mm interval under free breathing of 3-5 1/min oxygen. For three-dimensional treatment planning, the RPS700U software (Shimadzu Corporation) was used. The gross tumor volume (GTV) was delineated in the lung window. The GTV with a 5-mm margin was defined as the clinical target volume. Additional 5-6- $\mathrm{mm}$ margins for tumor motion were added in the cranio-caudal direction for internal target volume (ITV) creation. A uniform margin of $5 \mathrm{~mm}$ was used to calculate the planning target volume (PTV) from the ITV. Treatment plans were designed using 24-25 non-coplanar, irregularly shaped isocentric beams. Beam shaping was performed using a multi-leaf collimator with $1 \mathrm{~cm}$ width at the isocenter. The total dose was administered to the isocenter and conformably enclosed the PTV with the $90 \%$ isodose line. The prescribed doses were $50 \mathrm{~Gy} / 4$ fractions (Fr; 68 patients, $71.6 \%$ ), $50 \mathrm{~Gy} / 5 \mathrm{Fr}$ (20 patients, 21.1\%), $40 \mathrm{~Gy} / 4 \mathrm{Fr}$ (3 patients, 3.2\%), $50 \mathrm{~Gy} / 8 \mathrm{Fr}$ (2 patients, 2.1\%), $60 \mathrm{~Gy} / 8 \mathrm{Fr}$ (1 patient, $1.1 \%$ ) and $48 \mathrm{~Gy} / 4 \mathrm{Fr}$ (1 patient, 1.1\%). The dose constraints were applied as follows: Esophagus $\mathrm{V}_{40 \mathrm{~Gy}}<1 \mathrm{~cm}^{3}$; bronchus $\mathrm{V}_{40 \mathrm{~Gy}}<10 \mathrm{~cm}^{3}$; pulmonary artery $\mathrm{V}_{40 \mathrm{~Gy}}<1 \mathrm{~cm}^{3}, \mathrm{~V}_{40 \mathrm{~Gy}}<10 \mathrm{~cm}^{3}$; lung $\mathrm{V}_{20 \mathrm{~Gy}} \leq 20 \%, \mathrm{~V}_{15 \mathrm{~Gy}}$ $\leq 25 \%$; and spinal cord $\mathrm{D}_{\max }<25 \mathrm{~Gy}(3)$.

For treatment delivery, a Mitsubishi EXL-15DP linear accelerator (Mitsubishi Electric Corporation) was used with mainly 10-MV energy photon beans, occasionally using a 4-MV mixed beam to avoid regions receiving a higher than prescribed dose. The linear accelerator could not provide a 6-MV X-ray that is often used for lung SBRT. Each patient was immobilized and treated under free breathing of 3-5 1/min oxygen in the same manner as during the CT simulation. Usually, 5-6 fields were irradiated per day, amounting to 24-25 fields in total in order to improve the conformality and to reduce the dosage to the organs at risk. In each treatment session, the beam's eye view of each port was monitored, and the tumor location was confirmed using a TheraView electronic portal imaging device (Cablon Medical B.V.).

Follow-up. Follow-up examinations were performed in all patients. The first examination was 1 month after treatment; subsequently, the patients were followed up 3,6 and 12 months after treatment, and every 6 months thereafter. Each appointment included a spiral CT scan (slice thickness, $5 \mathrm{~mm}$ ) and a clinical examination. If necessary, positron emission tomography was performed.

All adverse effects were graded according to the National Cancer Institute's Common Terminology Criteria for Adverse Events (version 3.0) (15). The information on toxicities of grade $\geq 2$ was collected. All patients with interstitial pneumonia were diagnosed by pulmonologists using a bronchoscope, typical images and symptoms.

Statistical analysis. The statistical evaluation of LC, OS and cancer-specific survival (CSS) was performed using the Kaplan-Meier method. LC was defined as the duration from irradiation commencement to local tumor regrowth in the PTV or the last follow-up. OS was defined as the duration from irradiation commencement to death or the last follow-up. CSS was defined as the time interval from irradiation commencement to cancer-associated death or the last follow-up. Log-rank tests were used for the comparison of two survival curves. Univariate analysis using Fisher's exact test for discrete variables or Mann-Whitney $U$ test for continuous variables were used to explore potential prognostic indicators of grade $\geq 2$ radiation pneumonitis. In addition, univariate analyses using a log-rank test to determine the CSS and OS prognostic indicators we performed. All patients were divided into subgroups according to their median age, GTV, VC and FEV1/FVC. For forced expiratory volume/sec (FEV1.0), patients were divided into groups according to the Japanese Oncology Group Study 0403 criteria (9). $P<0.05$ was used to indicate a statistically significant results. All statistical analyses were conducted using the JMP statistical software (version 14.0; SAS Institute, Inc.).

\section{Results}

Patient characteristics. The characteristics of the patients included in the present study are summarized in Table I. The median follow-up period was 34 months (range, 1-89 months). A total of 87 patients $(92 \%)$ had an inoperable status due to 
Table I. Patient characteristics.

\begin{tabular}{|c|c|}
\hline Factors & Value or number $(\%)$ \\
\hline Age, median (range) years & $76(60-90)$ \\
\hline \multicolumn{2}{|l|}{ Sex } \\
\hline Male & $67(71)$ \\
\hline Female & $28(29)$ \\
\hline \multicolumn{2}{|l|}{ KPS } \\
\hline 90 & $1(1)$ \\
\hline 80 & $64(67)$ \\
\hline 70 & $15(16)$ \\
\hline 60 & $3(3)$ \\
\hline 50 & $11(12)$ \\
\hline 40 & $1(1)$ \\
\hline \multicolumn{2}{|l|}{ Smoking status } \\
\hline Current or previous & $79(83)$ \\
\hline Never & $12(13)$ \\
\hline Unknown & $4(4)$ \\
\hline \multicolumn{2}{|l|}{ Interstitial pneumonia } \\
\hline Yes & $1(1)$ \\
\hline No & $94(99)$ \\
\hline \multicolumn{2}{|l|}{ Treatment status } \\
\hline Initial treatment & $90(95)$ \\
\hline $\begin{array}{l}\text { Recurrence or residual } \\
\text { cancer after surgery }\end{array}$ & $5(5)$ \\
\hline \multicolumn{2}{|l|}{ Operable } \\
\hline Yes & $8(8)$ \\
\hline No & $87(92)$ \\
\hline \multicolumn{2}{|l|}{ Clinical stage } \\
\hline cT1aN0M0, stage IA & $32(34)$ \\
\hline cT1bN0M0, stage IA & $25(26)$ \\
\hline cT2aN0M0, stage IB & $38(40)$ \\
\hline \multicolumn{2}{|l|}{ Histology of primary lung cancer } \\
\hline Adenocarcinoma & $47(49)$ \\
\hline Squamous cell carcinoma & $29(31)$ \\
\hline Small cell carcinoma & $4(4)$ \\
\hline Unknown & $15(16)$ \\
\hline $\mathrm{VC}$, median (range) $\mathrm{cm}^{3}$ & $2,230(710-4,290)$ \\
\hline FEV1.0, median (range) $\mathrm{cm}^{2}$ & $1,220(410-2,550)$ \\
\hline \multicolumn{2}{|l|}{ Pattern of ventilatory impairment } \\
\hline Obstructive dysfunction & $47(49)$ \\
\hline Restrictive dysfunction & $22(22)$ \\
\hline Mixed dysfunction & $26(27)$ \\
\hline Total dose, median (range) Gy & $50(40-60)$ \\
\hline GTV, median (range) ml & $15.6(3.1-87.7)$ \\
\hline
\end{tabular}

KPS, Karnofsky performance status; VC, vital capacity; FEV1.0, forced expiratory volume in $1 \mathrm{sec}$; GTV, gross target volume.

poor pulmonary function and the presence of other comorbidities. The remaining eight patients $(8 \%)$ were considered to be operable but refused surgery. A total of 57 patients $(60 \%)$ had
Table II. Adverse effects.

\begin{tabular}{lccccc}
\hline & \multicolumn{4}{c}{ Grade, n (\%) } & \\
\cline { 2 - 5 } Variables & 2 & 3 & 4 & 5 & Total, n (\%) \\
\hline Dermatitis & $1(1)$ & 0 & 0 & 0 & $1(1)$ \\
Pneumonitis & $3(3)$ & $1(1)$ & 0 & $1(1)$ & $5(5)$ \\
Chest wall pain & $2(2)$ & $1(1)$ & 0 & 0 & $3(3)$ \\
Hemoptysis & 0 & 0 & 0 & $1(1)$ & $1(1)$ \\
\hline
\end{tabular}

stage IA (T1aN0M0 or T1bN0M0) and $38(40 \%)$ had stage IB (T2aN0M0) lung cancer. Regarding ventilatory impairment, $47(49 \%), 22(22 \%)$ and $26(27 \%)$ patients were classified as having obstructive dysfunction, restrictive dysfunction and mixed obstructive and restrictive dysfunction, respectively. The median FEV1/FVC value in patients with obstructive dysfunction during pretreatment spirometry testing was $58.6 \%$. The median $\% \mathrm{VC}$ in patients with restrictive dysfunction was $68.7 \%$. The median FEV1/FVC and \%VC in patients with mixed obstructive and restrictive dysfunction were 51.9 and $67.7 \%$, respectively. One patient (1\%) had interstitial pneumonitis.

Adverse effects. During the follow-up period, four patients (4\%) experienced grade $\geq 3$ toxicities. One patient (1\%), who had already received home oxygen therapy (HOT) due to interstitial pneumonia prior to SBRT, developed grade 5 radiation pneumonitis, and one (1\%) developed grade 3 radiation pneumonitis (Table II). In total, two patients ( $2 \%$ ) experienced grade $\geq 3$ radiation pneumonitis. Grade 3 chest wall pain was observed in one patient $(1 \%)$; one patient $(1 \%)$ who received re-irradiation using SBRT developed grade 5 hemoptysis. For this patient, the first SBRT was performed to the right S1 lung tumor, which did not include the trachea and the bronchus. After 57 months, recurrence was detected in the marginal zone of the initial SBRT. The recurrent tumor was located close to the pulmonary hilum. The second SBRT, which was used to treat the right S6 lung tumor with $60 \mathrm{~Gy} / 8 \mathrm{Fr}$ and the $95 \%$ dose line, partially included the right main bronchus. Consequently, grade 5 hemoptysis occurred following the second treatment with SBRT.

In the course of the clinical follow-up, 14 patients (14.7\%) eventually required HOT due to radiation pneumonitis in one patient and pulmonary disease deterioration in 13 patients. The average time until the introduction of HOT following SBRT was 25.8 months (range, 0.5-66.0 months). Of the 14 patients, eight survived for $>12$ months following HOT introduction.

Univariate analysis was performed to identify the potential risk factors of grade $\geq 2$ radiation pneumonitis across the different subgroups (Tables SI and SII). However, none of the patient, tumor or treatment characteristics were identified as risk factors. In addition, none of the factors observed in the pretreatment pulmonary function test were detected as significant risk factors.

Local control and survival. All patients completed the planned treatment. During the follow-up, 48 patients (51\%) 
Table III. Univariate analysis of cancer-specific survival and overall survival.

\begin{tabular}{|c|c|c|c|}
\hline Factor & No. of patients & Cancer-specific survival P-value & Overall survival P-value \\
\hline Age, years & & 0.766 & 0.338 \\
\hline$\geq 76$ & 50 & & \\
\hline$<76$ & 45 & & \\
\hline Sex & & 0.589 & 0.362 \\
\hline Male & 67 & & \\
\hline Female & 28 & & \\
\hline KPS & & 0.858 & 0.037 \\
\hline$<80$ & 30 & & \\
\hline$\geq 80$ & 65 & & \\
\hline Smoking status & & 0.310 & 0.775 \\
\hline Current or previous & 79 & & \\
\hline Never & 12 & & \\
\hline Operable & & 0.996 & 0.285 \\
\hline Yes & 8 & & \\
\hline No & 85 & & \\
\hline Clinical stage & & 0.223 & 1.000 \\
\hline IA & 57 & & \\
\hline IB & 38 & & \\
\hline Histology of primary lung cancer & & $<0.001$ & 0.003 \\
\hline Adenocarcinoma & 47 & & \\
\hline Squamous cell carcinoma & 29 & & \\
\hline Small cell carcinoma & 4 & & \\
\hline \multicolumn{4}{|l|}{ Pattern of ventilatory impairment } \\
\hline Obstructive dysfunction & 47 & 0.697 & 0.700 \\
\hline Restrictive dysfunction & 22 & & \\
\hline Mixed dysfunction & 26 & 0.497 & 0.510 \\
\hline \multicolumn{4}{|l|}{$\mathrm{GTV}, \mathrm{cm}^{3}$} \\
\hline$\geq 15.6$ & 48 & & \\
\hline$<15.6$ & 47 & & \\
\hline FEV 1.0, $\mathrm{cm}^{3}$ & & 0.669 & 0.979 \\
\hline$>700$ & 69 & & \\
\hline$\leq 700$ & 26 & & \\
\hline $\mathrm{VC}, \mathrm{cm}^{3}$ & & 0.981 & 0.214 \\
\hline$>2,282$ & 43 & & \\
\hline$\leq 2,282$ & 52 & & \\
\hline FEV1/FVC, \% & & 0.219 & 0.188 \\
\hline$>59.1$ & 47 & & \\
\hline$\leq 59.1$ & 48 & & \\
\hline
\end{tabular}

KPS, Karnofsky performance status; GTV, gross target volume; FEV1.0, forced expiratory volume in 1 sec; VC, vital capacity; FEV1.0/FVC, forced expiratory volume $\%$ in $1 \mathrm{sec}$.

died; 22 succumbed to cancer, 24 died of unrelated causes and two patients died of treatment-associated causes. The 3-year LC, CSS and OS rates were 78.8 (95\% CI, 67.2-87.15\%), 76.8 (95\% CI, 66.2-84.8\%) and 59.9\% (95\% CI, 49.1-69.7\%), respectively (Fig. 1). The median OS time was 34.0 months.

Considering clinical stage, the 3-year LC rate was $84.4 \%$ for Stage IA and $69.7 \%$ for Stage IB disease. The 3-year CSS rate was $80.3 \%$ for Stage IA and $71.0 \%$ for Stage IB disease.
The 3-year OS rate was $57.0 \%$ for Stage IA and $45.1 \%$ for Stage IB disease (data not shown).

Prognostic factors. Univariate analyses were performed to identify potential prognostic factors of CSS and OS among the different subgroups. The results revealed that the KPS was a significant predictor of OS $(\mathrm{P}=0.037)$, and that the histology of primary lung cancer was a significant predictor of CSS and 

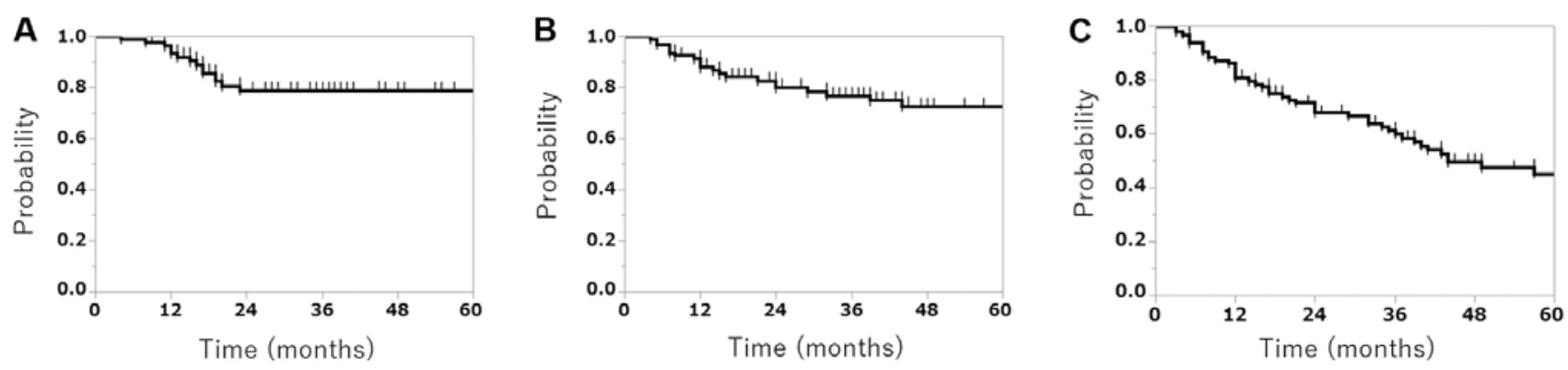

Figure 1. (A) Local control rate, (B) cancer-specific survival rate and (C) overall survival rate.

OS ( $\mathrm{P}<0.001$ and $\mathrm{P}=0.003$, respectively; Table III). In addition, the 3-year OS rates of patients with a KPS score $<80$ and those with a score $\geq 80$ were 46.6 and $65.5 \%$, respectively (Fig. 2A). The 3-year CSS rates of patients with adenocarcinoma, squamous cell carcinoma and small cell carcinoma were 81.3, 90.7 and $0 \%$, respectively (Fig. 2B). The 3-year OS rates of patients with adenocarcinoma, squamous cell carcinoma and small cell carcinoma were 68.7, 66.0 and 0\%, respectively (Fig. 2C). Although the associations between prognosis and pulmonary variables such as FEV1.0, VC and FEV1/FVC were also evaluated, no significant differences were identified.

\section{Discussion}

To the best of our knowledge, although several studies have focused on SBRT for patients with stage I lung cancer and poor pulmonary function, the safety and efficacy of the technique have not been clarified (16-18). The results of the present study demonstrated that SBRT is effective in patients with lung cancer and poor pulmonary function with acceptable toxicity. A KPS score $\geq 80$ was found to indicate favorable prognosis, and SBRT may be an effective and safe treatment option with a KPS score $\geq 80$ among patients with poor pulmonary function.

In the present study, one patient $(1.0 \%)$ who received re-irradiation by SBRT developed grade 5 hemoptysis. In this patient, the recurrent tumor was located close to the pulmonary hilum in the marginal zone of the initial SBRT. Consequently, the patient succumbed to hemoptysis due to tracheal hemorrhage. Subsequently, re-irradiation close to the pulmonary hilum was not performed for the other patients.

Radiation pneumonitis is the most commonly observed adverse effect following SBRT for lung cancer. Several studies using SBRT have reported that grade $\geq 3$ radiation pneumonitis is detected in 1.8-14.5\% of patients, although these studies include patients with normal pulmonary function $(5,8,9)$. Of 176 patients with severe COPD, Palma et al (11) reported that three patients $(2 \%)$ had grade 3 radiation pneumonitis. Chen et al (12) reported an occurrence rate of grade $\geq 3$ radiation pneumonitis or acute exacerbation of interstitial pneumonia in $18.8 \%$ of patients with lung cancer and coexisting interstitial pneumonia. The focus of the present study was on patients with lung cancer and poor pulmonary function, and only $2 \%$ of the patients developed grade $\geq 3$ radiation pneumonitis, although one patient (1\%) with HOT due to interstitial pneumonia prior to SBRT developed grade 5 radiation pneumonitis. This result suggested that the incidence of severe radiation pneumonitis following SBRT in patients with lung cancer and
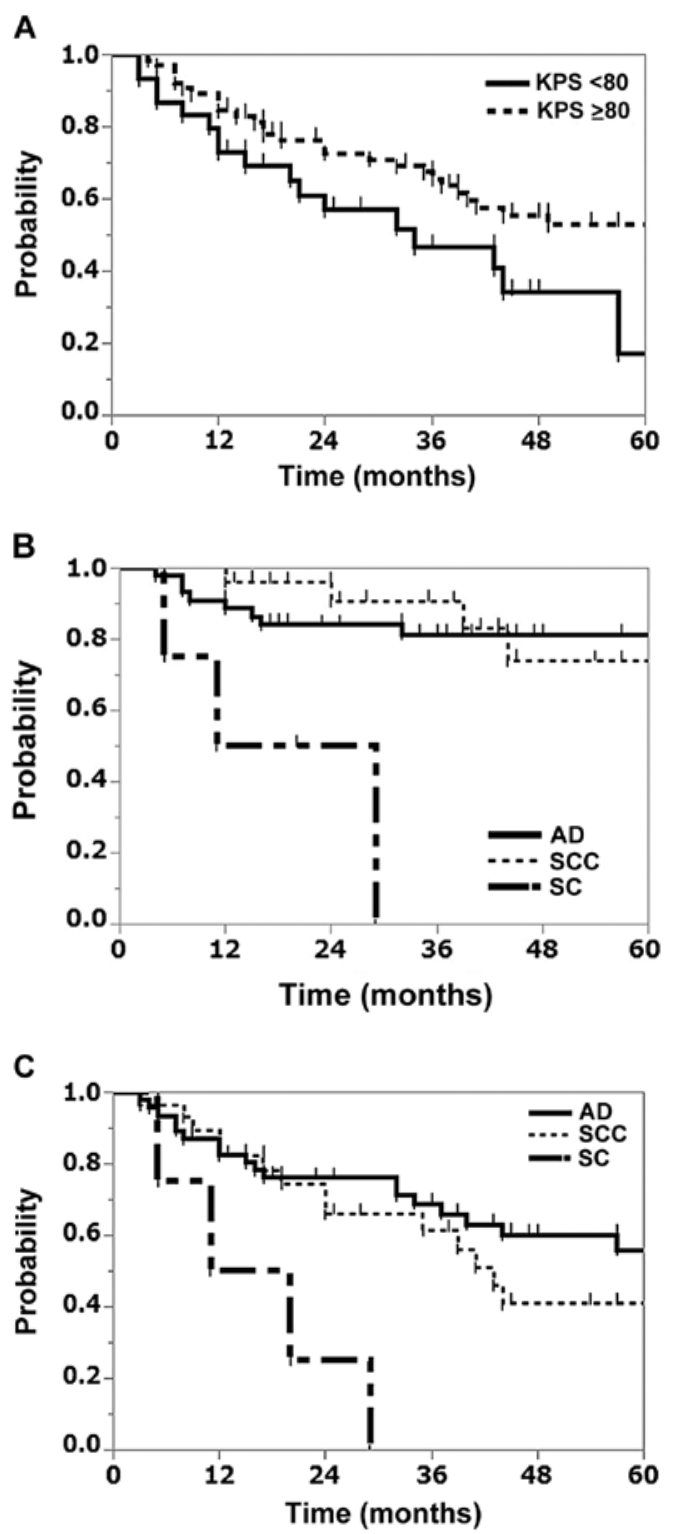

Figure 2. Local control or survival curves of different groups. (A) Overall survival rate according to KPS score, (B) cancer-specific survival rate according to the histology and (C) overall survival rate according to the histology. KPS, Karnofsky performance status; AD, adenocarcinoma; SCC, squamous cell carcinoma; SC, small-cell carcinoma.

poor pulmonary function is similar to that in patients with normal pulmonary function or COPD. Guckenberger et al (16) analyzed the influence of pretreatment pulmonary function on 
pulmonary toxicity following SBRT for early-stage NSCLC; no significant associations between any of the pretreatment pulmonary function parameters and the risk of either grade $\geq 2$ or $\geq 3$ radiation pneumonitis were observed. Similarly, the univariate analysis of potential risk factors of grade $\geq 2$ radiation pneumonitis in terms of average pulmonary function and dosimetric parameters in the present study indicated that none of the factors in the pretreatment pulmonary function test were significant risk factors, suggesting that SBRT use in patients with lung cancer and poor pulmonary function is relatively safe.

The reported 3-year LC and OS rates following SBRT for peripheral stage I lung cancer were 89-97.6 and 47-69\%, respectively $(5,8,9,11)$. In addition, LC and OS depend on clinical stage or operability $(8,19)$. Shibamoto et al (19) reported that the 3-year LC rate was $86 \%$ for Stage IA and $73 \%$ for Stage IB disease, and the 3-year OS rate was $74 \%$ for operable and $59 \%$ for inoperable patients. The results of the present study revealed that the 3-year LC rate was $78.8 \%$ for all patients, $84.4 \%$ for those with Stage IA disease and $69.7 \%$ for those with Stage IB disease. The 3-year OS rate was $59.9 \%$, although all 95 patients had poor pulmonary function, of which 87 patients $(92 \%)$ had an inoperable status. LC in the present study was slightly worse compared with previous findings, although the OS was consistent with the aforementioned studies. The reason for the lower LC is not clear; however, it was hypothesized that in patients with low pulmonary function, the tumor may be hypoxic and radio-resistant.

Previous studies on SBRT for lung cancer have identified several prognostic indicators such as T classification and COPD severity $(8,11)$. The univariate analysis in the present study identified KPS score as a significant predictor of OS $(\mathrm{P}=0.037)$, and primary lung cancer histology was a significant predictor of CSS $(\mathrm{P}<0.001)$ and $\mathrm{OS}(\mathrm{P}=0.003)$. This may arise from the fact that patients with a low KPS score generally have poor prognoses, or that small cell lung carcinoma is more aggressive compared with NSCLC. In addition, no significant differences were identified between prognoses and pulmonary variables such as FEV1.0, $\mathrm{VC}$ and FEV1/FVC in the univariate analysis, consistent with previous studies $(17,18)$. The results of the present study indicated that SBRT may be effective in patients with peripheral stage I lung cancer and poor pulmonary function.

The present study had several limitations. Firstly, this study was performed using a single-center retrospective design. Therefore, the possibility of selection bias cannot be eliminated. Secondly, the study sample size was limited. Finally, the total doses and fractionation varied (48-60 Gy in 4-8 Fr), which may have influenced tumor control, toxicity occurrence and severity.

SBRT for patients with peripheral stage I lung cancer and poor pulmonary function may be an effective treatment with acceptable toxicity, and a KPS score $\geq 80$ may indicate good prognosis.

\section{Acknowledgements}

Not applicable.

\section{Funding}

No funding was received.

\section{Availability of data and materials}

The datasets used and/or analyzed during the current study are available from the corresponding author on reasonable request.

\section{Authors' contributions}

$\mathrm{AK}, \mathrm{KH}$ and $\mathrm{MC}$ conducted this study and collected the data. YK collected the data. OS, YK and KO conducted the data analysis. $\mathrm{AK}$ and $\mathrm{KH}$ wrote the manuscript. $\mathrm{YK}$ and $\mathrm{KO}$ interpreted and analyzed the data. All authors have read and approved the manuscript.

\section{Ethics approval and consent to participate}

This study was approved by the Institutional Review Board of Osaka Rosai hospital (Sakai, Japan; approval no. 18D093g) and was conducted in accordance with the Declaration of Helsinki.

\section{Patient consent for publication}

Not applicable.

\section{Competing interests}

The authors declare that they have no competing interests.

\section{References}

1. Blomgren H, Lax I, Näslund I and Svanström R: Stereotactic high dose fraction radiation therapy of extracranial tumors using an accelerator. Clinical experience of the first thirty-one patients. Acta Oncol 34: 861-870, 1995.

2. Uematsu M, Shioda A, Suda A, Fukui T, Ozeki Y, Hama Y, Wong JR and Kusano S: Computed tomography-guided frameless stereotactic radiotherapy for stage I non-small cell lung cancer: A 5-year experience. Int J Radiat Oncol Biol Phys 51: 666-670, 2001.

3. Nagata Y, Takayama K, Matsuo Y, Norihisa Y, Mizowaki T, Sakamoto T, Sakamoto M, Mitsumori M, Shibuya K, Araki N, et al: Clinical outcomes of a phase I/II study of 48 Gy of stereotactic body radiotherapy in 4 fractions for primary lung cancer using a stereotactic body frame. Int J Radiat Oncol Biol Phys 63: 1427-1431, 2005.

4. Onimaru R, Shirato H, Shimizu S, Kitamura K, Xu B, Fukumoto S, Chang TC, Fujita K, Oita M, Miyasaka K, et al: Tolerance of organs at risk in small-volume, hypofractionated, image-guided radiotherapy for primary and metastatic lung cancers. Int J Radiat Oncol Biol Phys 56: 126-135, 2003.

5. Timmerman R, Paulus R, Galvin J, Michalski J, Straube W, Bradley J, Fakiris A, Bezjak A, Videtic G, Johnstone D, et al: Stereotactic body radiation therapy for inoperable early stage lung cancer. JAMA 303: 1070-1076, 2010.

6. Wulf J, Haedinger U, Oppitz U, Thiele W, Mueller G and Flentje M: Stereotactic radiotherapy for primary lung cancer and pulmonary metastases: A noninvasive treatment approach in medically inoperable patients. Int J Radiat Oncol Biol Phys 60: 186-196, 2004.

7. Xia T, Li H, Sun Q, Wang Y, Fan N, Yu Y, Li P and Chang JY: Promising clinical outcome of stereotactic body radiation therapy for patients with inoperable Stage I/II non-small-cell lung cancer. Int J Radiat Oncol Biol Phys 66: 117-125, 2006.

8. Baumann P, Nyman J, Hoyer M, Wennberg B, Gagliardi G, Lax I, Drugge N, Ekberg L, Friesland S, Johansson K-A, et al: Outcome in a prospective phase II trial of medically inoperable stage I non-small-cell lung cancer patients treated with stereotactic body radiotherapy. J Clin Oncol 27: 3290-3296, 2009. 
9. Nagata Y, Hiraoka M, Shibata T, Onishi H, Kokubo M, Karasawa K, Shioyama Y, Onimaru R, Kozuka T, Kunieda E, et al: Prospective trial of stereotactic body radiation therapy for both operable and inoperable T1N0M0 non-small cell lung cancer: Japan Clinical Oncology Group Study JCOG0403. Int J Radiat Oncol Biol Phys 93: 989-996, 2015.

10. Nagata Y and Kimura T: Stereotactic body radiotherapy (SBRT) for Stage I lung cancer. Jpn J Clin Oncol 48: 405-409, 2018.

11. Palma D, Lagerwaard F, Rodrigues G, Haasbeek C and Senan S: Curative treatment of Stage I non-small-cell lung cancer in patients with severe COPD: Stereotactic radiotherapy outcomes and systematic review. Int J Radiat Oncol Biol Phys 82: 1149-1156, 2012.

12. Chen H, Senan S, Nossent EJ, Boldt RG, Warner A, Palma DA and Louie AV: Treatment-related toxicity in patients with early-stage non-small cell lung cancer and coexisting interstitial lung disease: A systematic review. Int J Radiat Oncol Biol Phys 98: 622-631, 2017.

13. International Union Against Cancer: TNM Classification of Malignant Tumours. Sobin LH, Gospodarowicz MK and Wittekind C (eds). 7th edition. Wiley-Blackwell Inc., New York, NY, 2009.

14. Péus D, Newcomb N and Hofer S: Appraisal of the Karnofsky Performance Status and proposal of a simple algorithmic system for its evaluation. BMC Med Inform Decis Mak 13: 72, 2013.

15. U.S. Department of Health and Human Services, National Institutes of Health and National Cancer Institute: Common Terminology Criteria for Adverse Events (CTCAE). Version 4.0. https://www.eortc.be/services/doc/ctc/CTCAE_4.03_2010-06-14_ QuickReference_5x7.pdf. Accessed May 28, 2009.
16. Guckenberger M, Kestin LL, Hope AJ, Belderbos J, Werner-Wasik M, Yan D, Sonke J-J, Bissonnette JP, Wilbert J, Xiao Y, et al: Is there a lower limit of pretreatment pulmonary function for safe and effective stereotactic body radiotherapy for early-stage non-small cell lung cancer? J Thorac Oncol 7: 542-551, 2012.

17. Henderson M, McGarry R, Yiannoutsos C, Fakiris A, Hoopes D, Williams $\mathrm{M}$ and Timmerman R: Baseline pulmonary function as a predictor for survival and decline in pulmonary function over time in patients undergoing stereotactic body radiotherapy for the treatment of stage I non-small-cell lung cancer. Int J Radiat Oncol Biol Phys 72: 404-409, 2008.

18. Stone B, Mangona VS, Johnson MD, Ye H and Grills IS: Changes in Pulmonary Function Following Image-Guided Stereotactic Lung Radiotherapy: Neither Lower Baseline Nor Post-SBRT Pulmonary Function Are Associated with Worse Overall Survival. J Thorac Oncol 10: 1762-1769, 2015.

19. Shibamoto Y, Hashizume C, Baba F, Ayakawa S, Manabe Y, Nagai A, Miyakawa A, Murai T, Iwata H, Mori Y, et al: Stereotactic body radiotherapy using a radiobiology-based regimen for stage I nonsmall cell lung cancer: A multicenter study. Cancer 118: 2078-2084, 2012. 